\title{
A prática pedagógica mediada (também) pela língua de sinais: Trabalhando com sujeitos surdos*
}

\author{
Cristina B.Feitosa de Lacerda **
}

\begin{abstract}
RESUMO: Este trabalho pretende aprofundar aspectos da educação dos surdos, assumindo a língua de sinais como fundamental no processo educacional. Para tal, será focalizada uma classe de segunda série do ensino fundamental na qual foi inserido um aluno surdo, usuário da Língua Brasileira de Sinais (Libras), acompanhado de uma intérprete. $O$ foco das análises recairá sobre o papel da língua de sinais nas interações em sala de aula visando a contribuir para a discussão da educação dos sujeitos surdos.
\end{abstract}

Palavras-chave: Surdez, educação especial, linguagem, língua de sinais

Cada vez mais pesquisadores e professores têm procurado refletir sobre as práticas desenvolvidas nos diversos espaços educacionais, buscando ver, por meio da pluralidade de interesses dos vários sujeitos e de suas diferentes formas de interagir, modos de construção de conhecimentos e constituição da intersubjetividade, para melhor compreender a riqueza do funcionamento humano e as dinâmicas que ocorrem nesse contexto.

Nesse sentido, focalizar o olhar sobre a prática educacional que envolve os sujeitos surdos pode revelar-se muito interessante, já que abre uma perspectiva de discussão perante certas peculiaridades do funcionamento dos sujeitos e de dinâmicas em sala de aula que podem trazer contribuições importantes para a reflexão dos múltiplos papéis da instituição escolar.

A educação dos surdos tem se mostrado sempre como um assunto polêmico que requer cada vez mais a atenção de pesquisadores e estu-

\footnotetext{
* Pesquisa financiada pela Fapesp, com auxilio das bolsistas de iniciação científica Neiza Pacola e Fabiana M. Soares, financiadas pelo PIBIC-Unimep.

** Doutora em Psicologia da Educação, Unicamp. Docente do curso de fonoaudiologia da Unimep. E-mail: cristinalacerda@uol.com.br
} 
diosos da educação. As propostas educacionais desenvolvidas ao longo do último século não se mostraram eficientes e encontra-se um grande número de sujeitos surdos que após anos de escolarização apresentam uma série de limitações, não sendo capazes de ler e escrever satisfatoriamente e não tendo um domínio adequado dos conteúdos acadêmicos.

A atual política nacional de educação preconiza a educação integradora, ou seja, aquela organizada para atender a todos, incluindo os portadores de necessidades especiais (Alencar 1994). Essa política tem sustentação em documentos como a "Declaração de Salamanca" (Unesco 1994), resultado de uma conferência realizada em Salamanca (Espanha), em junho de 1994, com a presença da Unesco e de centenas de representações governamentais internacionais. O objetivo básico dessa declaração é promover a educação para todos (Perlin e Quadros 1997). Tal declaração deu força às discussões que confrontam e contrapõem a educação inclusiva e a educação especial para o atendimento às pessoas com necessidades especiais.

Contudo, a proposta da educação integradora, que vem sendo praticada há pelo menos três décadas no Brasil, é criticada por muitos, que entendem que nela subjaz a idéia de que é a criança quem deve se adaptar à escola, devendo ser inserida em um ambiente educacional o menos restritivo possível. Nesse sentido, é o aluno que precisa conquistar sua oportunidade para ser colocado na classe regular, demostrando suas habilidades de poder acompanhar os trabalhos propostos. Tais conceitos estão ligados, em certa medida, às formas tradicionais de educação especial (Unesco 1994).

A essas idéias contrapõe-se o movimento de inclusão, discutido em Salamanca, que tem como meta não deixar nenhum aluno fora do ensino regular, desde o início da escolarização, e propõe que é a escola que deve se adaptar ao aluno. Inclusão implica o compromisso que a escola assume de educar cada criança. Assim, a proposta de inclusão contempla a pedagogia da diversidade, pois todos os alunos deverão estar dentro da escola regular, independentemente de sua origem social, étnica ou lingüistica. Desse modo, para a implementação da inclusão, o modelo que se propõe é inspirado no caleidoscópio, no qual cada peça é importante para garantir a beleza e a riqueza do todo, ou seja, é desejável que na classe regular haja todo tipo de aluno para que o grupo se enriqueça. Para tal, a escola deve ser criativa para buscar soluções visando à manutenção desse aluno no espaço da sala de aula regular, levando-o a obter resultados satisfatórios em seu desempenho acadêmico e social (Mazzota 1996, Kelman 1998).

Historicamente, vários estudos apontam para fracassos e insucessos, prós e contras, tanto do ensino especial, exclusivamente voltado para 0 
atendimento da pessoa surda, como da inserção desses sujeitos no ensino regular (Revista Espaço 1997). Geralmente, essa discussão precede outra, não menos importante, que indica a dificuldade que os surdos têm, após anos de escolarização, para ler e escrever de forma satisfatória, qualquer que seja o modelo educacional escolhido (educação especial ou ensino regular). As pessoas surdas vêm sendo escolarizadas, mas essa escolarização tem produzido poucos resultados realmente efetivos.

Durante muitas décadas o trabalho educacional voltado para as pessoas surdas pautou-se nos princípios do oralismo (Goldfeld 1997). Na perspectiva de que ensinar os surdos a falar era a tarefa mais importante, criaram-se experiências de educação especial ou de educação integradora sem que ambas, no entanto, mostrassem resultados acadêmicos satisfatórios. A maior parte dos surdos profundos, por exemplo, não desenvolveu uma fala socialmente inteligível, e, em geral, o desenvolvimento alcançado foi parcial e tardio em relação à aquisição de fala apresentada pelos ouvintes, implicando um atraso de desenvolvimento global significativo. Somadas a isso, estavam as dificuldades ligadas à aprendizagem da leitura e da escrita. Sempre tardia, cheia de problemas, mostrando sujeitos, muitas vezes, apenas parcialmente alfabetizados após anos de escolarização (Johnson et al. 1991, Fernandes 1989).

Já em 1926, Vygotsky (1986) criticava as práticas educacionais vigentes para a educação dos surdos e também o modo como a língua falada era ensinada, argumentando que, tal como era realizada, tomava muito tempo da criança, em geral não Ihe ensinando a construir logicamente uma frase. O trabalho (naquela época e contemporaneamente) era dirigido para uma "recitação" e não para a aquisição de uma linguagem propriamente dita, resultando em um vocabulário limitado e, muitas vezes, sem sentido, configurando uma situação extremamente difícil e confusa. Vygotsky, então, comentava que a problemática dos surdos aparece brilhantemente resolvida nas teorias, mas que na prática não se observam os resultados desejados.

Essa discussão mantém-se atual. Verifica-se ainda, com muita freqüência, práticas de educação que visam a uma produção de fala que faz pouco ou nenhum sentido para os surdos e que os faz despender horas importantes em treinos que não levam à aprendizagem de uma linguagem. $O$ verdadeiro problema parece estar no fato de que a linguagem oral precisa ser ensinada; o que ocorre normalmente com os ouvintes é que ela é adquirida, sem que para isso haja qualquer procedimento "especial".

Diante dessa problemática bastante complexa, vários pesquisadores e educadores tentam, há algum tempo, buscar soluções mais efica- 
zes para a educação das pessoas surdas (Ciccone 1996). Contudo, muitos desses estudos apontam para as dificuldades de linguagem dos surdos e discutem a necessidade de se buscar prioritariamente uma solução para esse aspecto (Góes 1996, Lacerda 1996).

Tais problemas motivaram o surgimento de estudos sobre as línguas de sinais utilizadas pelas comunidades surdas. Tais estudos (Stokoe 1978 e Volterra 1984, entre outros) revelaram que as línguas de sinais são verdadeiras línguas, preenchendo em grande parte os requisitos que a lingüística coloca para as línguas orais. Eles colaboraram também para indicar que a linguagem de sinais desenvolvida pelas comunidades surdas é a forma de linguagem mais acessível aos surdos, pois é considerada sua língua natural; mesmo sem ouvir, eles podem ser competentes em uma língua visogestual, capaz de favorecer seu desenvolvimento integral, contribuindo para sua constituição como sujeitos (Marchesi 1987). Outros estudos, como os de Bouvet (1990), mostram ainda que as línguas de sinais são adquiridas pelos surdos com naturalidade e rapidez, pois permitem uma comunicação eficiente e completa como aquela desenvolvida por sujeitos ouvintes, possibilitando aos surdos um desenvolvimento cognitivo, social e, em outros aspectos, muito mais adequado, compatível com a faixa etária. Estudos feitos no Brasil apontam para resultados semelhantes (Brito 1995, Quadros 1997).

Com base em tais conclusões, iniciou-se um movimento visando incorporar as línguas de sinais das comunidades surdas às práticas educacionais. Surge então a abordagem bilíngüe para a educação de surdos, a qual preconiza que o surdo deve ser exposto o mais precocemente possível a uma língua de sinais, identificada como uma língua passível de ser adquirida por ele sem que sejam necessárias condições especiais de "aprendizagem". A proposta educacional que envolve a língua de sinais permite o desenvolvimento rico e pleno de linguagem, possibilitando ao surdo um desenvolvimento integral. A proposta de educação bilíngüe defende, ainda, que também seja ensinada ao surdo a língua da comunidade ouvinte na qual está inserido, em sua modalidade oral e/ou escrita, sendo que esta será ensinada com base nos conhecimentos adquiridos por intermédio da língua de sinais.

Nesse modelo, o que se propõe é que sejam aprendidas duas línguas, a língua de sinais e, secundariamente, a língua do grupo ouvinte majoritário. Para que as interações possam fluir, a criança surda é exposta o mais cedo possível à língua de sinais, aprendendo a sinalizar tão rapidamente quanto as crianças ouvintes aprendem a falar. Ao sinalizar, a criança desenvolve sua capacidade e sua competência lingüística, numa língua que lhe servirá depois para aprender a língua falada, do grupo majoritário, como segunda língua, tornando-se bilíngüe, numa modalidade de bilingüismo sucessivo. 
O objetivo da educação bilíngüe é que a criança surda possa ter um desenvolvimento cognitivo-lingüístico equivalente ao verificado na criança ouvinte, e que possa desenvolver uma relação harmoniosa também com ouvintes, tendo acesso às duas línguas: a língua de sinais e a língua do grupo majoritário.

A filosofia bilíngüe possibilita também que, dada a relação entre o adulto surdo e a criança surda, esta possa construir uma auto-imagem positiva como sujeito surdo, sem perder a possibilidade de integrar-se numa comunidade de ouvintes. A língua de sinais poderia ser introjetada pela criança surda como uma língua valorizada, o que até hoje tem sido bastante difícil, apesar de esta ocupar um lugar central na configuração das comunidades surdas (Moura 1993).

As experiências com educação bilíngüe ainda são recentes, poucos países têm esse sistema implantado há mais de uma década. A aplicação prática do modelo de educação bilíngüe não é simples e exige cuidados especiais, formação de profissionais habilitados, diferentes instituições envolvidas com tais questões etc. Tais práticas remetem a um universo amplo de questões ainda pouco explorado, que parece apresentar vários problemas, ao mesmo tempo em que aponta para formas de atendimento mais adequadas às pessoas surdas.

Em diversos países, como no Brasil, as experiências com educação bilíngüe ainda estão restritas a alguns poucos centros. O uso acadêmico da língua de sinais mostra-se bastante complexo. As escolas especializadas no atendimento aos surdos, em geral, contam com professores ouvintes que fazem um uso insatisfatório da língua de sinais. Muito freqüentemente, a língua de sinais é usada como apoio para a linguagem oral e não como uma língua propriamente (Moura 1993). Além disso, tais escolas não possuem uma pedagogia desenvolvida para esse fim e acabam servindo-se de estratégias pedagógicas desenvolvidas para os ouvintes, o que dificulta ainda mais a aprendizagem dos surdos (Trenche 1995).

Em contrapartida, ao optar pela inserção do aluno surdo na escola regular, isso precisa ser feito com certos cuidados que visem garantir sua possibilidade de acesso aos conhecimentos que estão sendo trabalhados, considerando as peculiaridades lingüisticas desses sujeitos.

Nessa perspectiva, uma possibilidade de inserção do aluno surdo nas classes regulares é ele ser acompanhado de um intérprete de língua de sinais. Dessa forma, o aluno recebe a informação escolar na língua de sinais, que é sua língua de domínio, de uma pessoa com competência nessa língua. Ao mesmo tempo, o professor ouvinte ministra suas aulas sem se pre- 
ocupar em como passar esta ou aquela informação em sinais, atuando em uma língua que domina.

É preciso que haja um reconhecimento de que os alunos necessitam de apoio específico, de forma permanente ou temporária, para alcançar os objetivos finais da educação e, então, devem ser oferecidos, por exemplo, apoios tecnológicos e humanos. Um desses apoios humanos é o intérprete de língua de sinais, o qual foi incorporado há poucos anos em experiências de educação integradora na América Latina; inicialmente, em nível de segundo grau e universitário, como discute Famularo (1999).

Essa alternativa, usada em diversos países (especialmente nos Estados Unidos) e ainda experimental no Brasil, abre uma série de novas implicações para as práticas pedagógicas. Em primeiro lugar, o espaço escolar tradicional passa a aceitar que outra língua circule no meio acadêmico, além daquela de domínio do grupo majoritário (ouvinte), dando a essa língua um status social de pertinência. Assim, o surdo é valorizado em sua língua, e um intérprete (competente em sinais) é quem, por meio dos sinais, propicia seu acesso aos conhecimentos acadêmicos. Ao mesmo tempo, o aluno surdo pode partilhar dos temas acadêmicos de forma integral - e não de forma reduzida, especialmente criada para ele, como é freqüente nos espaços de educação especial (Vygotsky 1986). O surdo tem acesso aos conhecimentos da cultura à qual pertence por intermédio de uma língua que ele domina.

Tal experiência pode ampliar as discussões sobre os caminhos no trabalho com crianças surdas. $O$ surdo precisa ser respeitado em sua condição lingüística e, na medida em que tal condição é respeitada, ele pode se desenvolver e construir novos conhecimentos de maneira adequada e satisfatória. Mas, para que isso ocorra, é preciso que sejam geradas algumas condições especiais, respeitando e propiciando o desenvolvimento e o uso de sua linguagem. É preciso que os profissionais envolvidos no trabalho com as pessoas surdas estejam atentos a isso.

\section{Metodologia}

Em estudos recentes que focalizam aspectos metodológicos, especialmente em áreas como as das ciências humanas, é crescente o reconhecimento de que a linha teórica eleita pelo pesquisador tende a ser determinante da metodologia por ele adotada (Castro 1996). "Ao recuperar a história do dado, por meio da descrição de suas condições de produção, podem (os estudos feitos nessa linha) permitir identificar a constituição histórica do sentido" (Perroni 1996, p.22) 
O objeto de estudo é a língua em atividade e a relação dos sujeitos com ela; reconhecendo o desenvolvimento como um processo dinâmico, em constante fluxo, busca-se dar conta da continuidade dos fatos, uma vez que a realidade é vista como um processo em constante movimento, e o foco das análises está dirigido para a emergência dos processos de mudança e permanência das dinâmicas próprias de sala de aula e das interações entre os sujeitos que constituem o espaço escolar.

Assim sendo, os dados analisados foram construídos, pois assumese que eles se configuram com base em um processo de elaboração ao qual são submetidos os fatos. Além disso, a análise desenvolvida leva em consideração, também, aquilo que é particular e global na ocorrência dos fatos. Essa questão admite, na verdade, duas dimensões: uma delas diz respeito à importância de se atentar para os fatos singulares, uma vez que estes podem conter informações relevantes que as abordagens de caráter global, por sua natureza, são levadas a desconsiderar (Ginzburg 1987). A outra se refere às múltiplas inter-relações que se estabelecem entre instâncias, tais como a educação como prática social, os processos de significação, os processos de subjetivação e a construção da identidade.

O ponto de interesse para análise se concentrará na dinâmica própria de interlocução que se estabelece em sala de aula, focalizando o papel da língua de sinais nos processos de interação e como ela contribui para que o aluno surdo e os alunos ouvintes construam novos conhecimentos.

Para o desenvolvimento do estudo realizaram-se videogravações semanais na sala de aula freqüentada pela criança surda, com a duração de aproximadamente uma hora. A sala focalizada é uma segunda série do ensino fundamental e a classe era composta por 11 alunos, sendo 3 meninas e 8 meninos, na faixa etária de 8 a 9 anos.

A criança focalizada é portadora de surdez profunda bilateral, não tem domínio do português falado e é usuária da língua brasileira de sinais ( $\mathrm{Li}$ bras). Ela foi acompanhada em suas atividades diárias na escola por uma intérprete de Libras, na tentativa de oferecer a ela uma escolarização adequada, na qual a língua de sinais fosse contemplada, já que na região em que vive não existe nenhuma escola especial para surdos que trabalhe numa perspectiva de educação bilíngüe. A intérprete de Libras é também professora de surdos, tem um domínio razoável da língua de sinais e tem o português como sua língua materna.

Os registros foram transcritos integralmente, respeitando-se a linguagem oral da professora e dos alunos ouvintes, além dos sinais e gestos produzidos para a comunicação com a criança surda. Para a transcrição foram 
usados os parâmetros e a legenda proposta por Lacerda (1996): (entre parênteses) - estão gestos ou comportamentos dos interlocutores; /ENTRE BARRAS E EM MAIÚSCULAS/ - estão os sinais da Libras; em itálico - estão as falas entre os interlocutores; EM MAIÚSCULAS - palavras escritas.

\section{A língua de sinais e o espaço escolar}

Para que se faça uma discussão conseqüente do uso da língua de sinais nesse espaço escolar, mostra-se como oportuno apresentar um episódio que será analisado em seguida.

Como tarefa de casa, Gui havia escrito o seguinte texto em seu caderno:

HOJE É QUINTA MANHÃ BONITA,

AMANHÃ É SEXTA, DIA DE FESTA

PORQUE DEPOIS É SÁBADO, DIA FOLGADO

DEPOIS É DOMINGO, EU FICO DORMINDO.

A intérprete de Libras pede que Gui leia sua produção para toda a classe enquanto ela irá traduzindo; ele fica relutante e desinteressado em realizar essa tarefa.

Gui- /HOJE/ /HOJE/

Intérprete- /AMANHÃ/

Gui- /AMANHÃ/

Intérprete- (Aponta a folha para Gui)

Gui- (Olha para sua folha) /SEXTA/

Intérprete- (Sorri e movimenta a cabeça positivamente)

Gui- /FESTA/

Intérprete- /JÓIA/ (aponta a folha de Gui)

Gui- /PORQUE/ /QUAL/?

Intérprete- /DEPOIS/

Gui- /É/ /DIA/

Intérprete- /SÁBADO/ /O QUÊ/?

Gui- /DIA/ /FESTA/

Intérprete- /NÃO/ (aponta a folha) 
Gui- (Olha para a folha)

Intérprete- (Toca Gui para chamá-lo, porque estava distraído)

Gui- (Olha para Intérprete)

Intérprete- /FOLGADO/ /VOCÊ/

Gui- (Olha para Professora e movimenta a cabeça negativamente)

P- (Observava a leitura, olha para Gui e põe as mãos na cintura)

Gui- (Olha para Professora e faz um gesto de que não sabe, com as mãos)

Professora- /AGORA/ /ESPERAR//VOCÊ//FORTE/ /CANSADO/ ?

(põe as mãos na cintura)

Gui- (Para Professora) /HOJE/ /É/ /QUARTA/

Professora- (Para a classe) Vamos lá gente, agora ele tá fazendo...

Gui- (Olha para Professora, movimenta a cabeça negativamente)

Professora- Ele não tá é com vontade de fazer.

Gui- /HOJE/ (coloca as mãos no queixo e movimenta a cabeça negativamente)

Professora- Só um pouquinho... (fala ininteligível) /POUCO/

Gui- (Continua com as mãos no queixo e movimentando a cabeça negativamente)

Professora- Vejam, vamos olhar pro Gui, ele vai fazer sinal pra gente ver, vamos ver se a gente consegue entender o que ele vai fazer.

Intérprete- /TODOS/ /OLHAR/ /VOCÊ/ /SINAL/ /JÓIA/?

Gui- (Olha para Intérprete)

Intérprete- (Aponta a folha)

Gui- /HOJE/ /É/ /QUARTA/

Intérprete- (Olha para Gui interrogando-o, movimenta a cabeça negativamente e volta a apontar sua folha)

Gui- /O QUE/? /QUINTA/?

Intérprete- (Sorri) /QUINTA/ (volta a apontar a folha para Gui) /ESPERAR/

Gui- /DIA//FOLGADO/

Gui- /FOLGADO/ (Olha para Intérprete)

Intérprete- (Aponta para a palavra DEPOIS)

Gui- /DEPOIS/ (Realizando o sinal de forma imprecisa)

Intérprete- /DEPOIS/ (dando ênfase à produção adequada do sinal) /DEPOIS/

(Volta a apontar a palavra escrita)

Gui- /É/ /DOMINGO/ / QUAL?/

Intérprete- (Aponta para o texto escrito)

Gui- /EU/ (Expressão interrogativa em relação à próxima palavra escrita) 
Intérprete- /VER??/ /DORMIR??/

Gui- (Movimenta a cabeça negativamente) /VER/ /NÃO/

Intérprete- /DORMIR??/ (movimenta a cabeça afirmativamente)

Gui- (Movimenta a cabeça afirmativamente)

Aluno - Eu fico dormindo. (Aluno que estava ao lado de Gui acompanhando a leitura)

Intérprete- /FICAR/ /DORMIR/ (olha para Gui)

Intérprete- /VOCÊ//NÃO/ /SABER/????

Gui- (Olha para Intérprete e sorri)

Intérprete- (Levanta-se e faz cócegas em Gui)

Gui- (sorri)

Professora- Você oh!!! (Se aproxima da mesa de Gui e pega a folha de sua mesa)

Gui- (Olha para Professora, solicita algo que não é registrado pela filmadora)

Professora- Ah... agora não, depois. Na hora do lanche. /AGORA/ /NÃO/ (estala os dedos para chamar Gui) /DEPOIS/ /COMER/ /AGORA/ /NÃO/ (Aponta para todos os alunos e indica a folha escrita de Gui que está em suas mãos)

Professora- Ele escreveu assim... Hoje... Vamos todo mundo fazer sinal para ele ver que a gente sabe fazer sinal? Então vamos lá... Hoje /HOJE/ é, é quinta, Manhã... /MANHÃ// (olha para Intérprete para certificar-se de que está sinalizando corretamente)

Intérprete- (Olha para Professora) /MANHÃ/

Professora- Manhã bonita. Amanhã é sexta, dia de festa. Porque depois é sábado dia folgado. Depois é domingo e eu fico dormindo.(A professora lê devagar acompanhando os sinais produzidos pelos alunos)

Alunos- (Fazem os sinais acompanhando a produção da intérprete)

Professora- (Vai até a mesa de Gui) /VOCÊ/ (abaixa para falar com Gui e aponta sua folha)

Gui- (Olha para Professora)

Professora- /HOJE/ /NÃO/ /É/ /DOMINGO/ (Volta a mostrar a folha) / HOJE/ /QUARTA/ /VOCÊ//FOLGADO/?

Gui- (Olha para Professora e sorri).

Para uma análise adequada desse episódio é preciso que se considere uma série de fatores importantes característicos de Gui. Primeiramente, é preciso que se diga que no momento em que foi registrado o episódio ele ainda não estava plenamente alfabetizado. Gui lia e escrevia quando auxiliado, elaborando hipóteses sobre a leitura e a escrita, mas sem ter to- 
tal domínio do uso desse material. Ele, provavelmente, realizou a tarefa de casa com a ajuda de familiares (o que ocorria freqüentemente, com ele expressando em sinais suas idéias e a mãe ou o pai escrevendo para ele, ou auxiliando-o a escrever). A tarefa proposta em sala de aula - ler para toda a turma sua produção - envolvia um problema adicional que era sua real dificuldade de leitura. Observa-se na situação a participação da intérprete procurando dar sentido, traduzir suas idéias, resgatar palavras já trabalhadas ou conhecidas, mas ele parece pouco motivado para a atividade.

Nesse momento, a professora, percebendo as dificuldades de Gui, incentiva-o a continuar lendo já que esta era a proposta seguida por todos os alunos. Em seguida, ela propõe que a turma toda leia em sinais o texto produzido por ele. Ela assume a língua de sinais como uma língua pertencente àquele grupo e propõe uma atividade de leitura um tanto "difícil" para as crianças ouvintes (afinal, nem todas têm domínio dos sinais e precisariam de ajuda para realizar aquela leitura).

A professora conhece as dificuldades de Gui e procura criar condições para que tais dificuldades sejam superadas; ao mesmo tempo, procura integrá-lo ao grupo, mostrando as dificuldades da classe com o manejo da língua de sinais. Toda a atividade é perpassada pela língua de sinais, que se mostra como um caminho para alcançar os objetivos pretendidos e para realizar as interações peculiares ao espaço escolar.

Ao envolver os demais alunos, ela deixa ver "as dificuldades de leitura" em sinais de todo o grupo, tornando, de certa forma, o grupo simétrico às dificuldades de leitura apresentadas por Gui. Os alunos assumem seu desconhecimento e necessitam, nesse momento, da ajuda da intérprete para realizar a tarefa de leitura. Gui motiva-se com a proposta da professora e participa de forma mais ativa. É muito instigante ver como a língua de sinais perpassa todo o grupo, provocando situações de construção de conhecimento e interação.

É possível vislumbrar a multiplicidade de fatores interferentes em uma prática assim estruturada e, ao mesmo tempo, mostrar que a língua de sinais pode estar presente no espaço de sala de aula, colaborando para as relações que envolvem todo o espaço educacional.

Não há prejuízos trazidos pela presença dessa língua em sala de aula; ao contrário, ela impõe uma diversidade que torna a linguagem um objeto de constante reflexão. Abre possibilidades para que todos, ouvintes e surdo, se pensem e se repensem nas relações com os objetos de conhecimento.

Gui pode escrever, ler, compreender sua produção, partilhando suas conquistas com os demais colegas e tudo isso ocorre pela mediação da lín- 
gua de sinais. A professora pode dirigir-se a ele, exigir dele maior esforço para superar dificuldades e também pode identificar problemas, porque respeita, conhece e aceita a língua de sinais não só como a língua do aluno surdo, mas como uma língua que pertence ao espaço escolar. Tais respeito, conhecimento e aceitação são explicitados na medida em que a professora aceita a presença da intérprete em sala de aula, dividindo e negociando espaços, possibilitando que relações de construção de conhecimento se estabeleçam.

O conhecimento dos sinais pelos ouvintes (professora e alunos) foi construído nas atividades cotidianas em que Gui estava envolvido. Não houve um trabalho especial de "aprendizagem" dos sinais, mas um contato com a língua que os levou ao domínio de uma série de sinais. As crianças ouvintes e a professora passaram a fazer uso desses sinais, cada vez com maior intimidade e segurança, permitindo uma maior aproximação com o sujeito surdo e com a própria língua.

O dado aqui analisado revela a oportunidade aberta por tal prática para a construção de uma condição bilíngüe especial para o sujeito surdo. Além disso, mostra que a língua de sinais pode ser acolhida positivamente pelos ouvintes, possibilitando o rompimento de barreiras sempre tão comuns em relação a ela. Contudo, faz-se necessário esclarecer que os propósitos desse estudo não são os de defender os pressupostos da inclusão. Foi a falta de uma escola apropriada na região em que a criança reside que gerou a necessidade de uma organização do espaço educacional atípica, aqui estudada. Uma escola especialmente organizada para o atendimento das pessoas surdas, na qual todos os conteúdos acadêmicos fossem ministrados em sinais, por um professor com domínio de Libras, em meio a usuários de Libras, seria o ambiente acadêmico desejável para o desenvolvimento pleno da pessoa surda.

Todavia, o espaço pedagógico "alternativo" criado pode, ao ser estudado, ajudar a compreender vários aspectos da relação surdos/ouvintes. A experiência aqui focalizada pretende, fundamentalmente, dar visibilidade a um espaço possível de contato entre duas comunidades diferentes (a dos surdos e a dos ouvintes) dentro de uma instituição educacional. Esse contato revela tensões, dificuldades de articulação, impasses - que não convergem, contudo, para um confronto, mas sim para ajustes, negociações e trocas que apontam para infinitas possibilidades de composição dentro do espaço educacional. Para que isso ocorra, é necessário, entretanto, que os atores dessa cena aceitem o desafio de compreender as diferenças como mútuas e procurem, verdadeiramente, atuar nesse espaço de contato, assumindo a diversidade, modificando- 
se, numa multiplicidade de estratégias que não visem a "padronizar" o diferente, mas interagir com ele na plenitude de suas peculiaridades.

The pedagogical practice (also) mediated by sign language: Working with deaf people

ABSTRACT: This study intends to deepen the aspects of the deafs' education taking the sign language as fundamental in the educational process. Thus, it will be focused a second grade class of the elementary level in which a deaf student will be introduced. This deaf student uses LIBRAS (Brazilian Sign Language) and he will be accompanied by an interpreter. The focus on the analyses will revert on the role of sign language over the interaction in the classroom aiming at contributing to a discussion of the deafs' education.

Referências bibliográficas

ALENCAR, E.M.L.S. de (org.). Tendências atuais e desafios da educação especial. Brasília: MEC, 1994. Série Atualidades Pedagógicas.

BOUVET, D. The path to linguage: Bilingual education for children. Filadélfia: Multilingual Matters, 1990.

BRITO, L.F. Por uma gramática de língua de sinais. Rio de Janeiro: Tempo Brasileiro, 1995.

CASTRO, M. F. P. (org.), O método e o dado no estudo da linguagem. Campinas: Editora da UNICAMP, 1996

CICCONE, M. Comunicação total. $2^{\underline{a}}$ ed. Rio de Janeiro: Cultura Médica, 1996.

FAMULARO, R. "Intervención del intérprete de lengua de señas/lengua oral em el contrato pedagógico de la integración". In: SKLIAR, C (org.). Atualidade da educação bilingüe para surdos. Porto Alegre: Mediação, 1999.

FERNANDES, E. Problemas lingüísticos e cognitivos dos surdos. Rio de Janeiro: Agir, 1989.

GINZBURG, C. O queijo e os vermes. São Paulo: Companhia das Letras, 1987.

GÓES, M.C.R. Linguagem, surdez e educação. Campinas: Autores Associados, 1996.

GOLFELD, M. A criança surda. São Paulo: Plexus, 1997. 
JOHNSON, R.E.; LIDDELL, S.K. e ERTINGUI, C.J. Educazione degli studenti sordi. Principi per facilitare l'acesso ai programmi di studio. Roma: Anicia, 1991.

KELMAN, C.A. "Surdez e inclusão". Anais do III Congresso Ibero-americano de Educação Especial. Foz do Iguaçu: MEC, vol. 3, 1998.

LACERDA, C.B.F. de. "Os processos dialógicos entre aluno surdo e educador ouvinte: Examinando a construção de conhecimentos". Tese de doutorado, Faculdade de Educação, Unicamp, 1996.

MARCHESI, A. El desarrollo cognitivo e lingüístico de los ninõs sordos: Perspectivas educativas. Madri: Alianza, 1987.

MAZZOTA, M.J.S. Educação especial no Brasil: História e políticas. São Paulo: Cortez, 1996.

MOURA, M.C. "A língua de sinais na educação da criança surda". In: MOURA, M.C. et alli. Língua de sinais e educação do surdo. São Paulo: Tec Art, 1993.

PERLIN, G.T.T. e QUADROS, R.M. "Educação de surdos em escola inclusiva?". Revista Espaço, vol. 7. Rio de Janeiro: Ines, 1997.

PERRONI, M. C. "O que é o dado em aquisição da linguagem?". In: CASTRO, M. F. P. (org.), O método e o dado no estudo da linguagem. Campinas: Editora da UNICAMP, 1996

QUADROS, R.M. A educação de surdos: A aquisição de linguagem. Porto Alegre: Artes Médicas, 1997.

REVISTA ESPAÇO. Vol. 7. Rio de Janeiro: Ines, 1997.

SKLIAR, C. (org.). Educação e exclusão: Abordagens socioantropológicas em educação especial. Porto Alegre: Mediação, 1997.

STOKOE, W. Sign language struture. Ed. rev. Silver Spring: Listok Press, 1978.

TRENCHE, M.C.B. "A criança surda e a linguagem no contexto escolar". Tese de doutorado. São Paulo: PUC-SP, 1995.

UNESCO. "Declaração de Salamanca" e "Linha de ação sobre necessidades educativas especiais". Brasília: Corde, 1994.

VYGOTSKY, L.S. Fondamenti di difettologia. Roma: Bulzoni, 1986.

VOLTERRA, V. La lingua dei segni italiana: LIS. Roma: Istituto di Psicologia, CNR, 1984. 